\title{
Study on the Function Pathway of the Agricultural Eco-capital Operation to Poverty Alleviation in Hubei Enshi
}

\author{
Yi-Fei MA ${ }^{1, a}$ \\ ${ }^{1}$ School of Business Administration, Zhongnan University of Economics and Law, Hubei Wuhan, \\ 430073, China \\ aemail:775694276@qq.com
}

\section{Keywords: Agricultural Eco-capital Operation; Poverty Alleviation; Function Pathway}

\begin{abstract}
It is a hard task that the alleviating poverty work should be finished with good quality on time during the new process of ecological civilization in China. To achieve this goal, the method of agricultural ecological capital operation can be an effective way, as it can use regional ecological resources advantage to develop economy as well as protect environment. This paper takes Enshi Prefecture where is a poor place in poverty but rich in natural resources as object. Then, according to the effectiveness of Enshi's agricultural ecological capital operation in poverty alleviation, this paper analyses the function pathways in its agricultural ecological industry, technology, and consciousness and restoration mechanism. Finally, it proves that this method can help alleviate the four-fold poverties of economy, substance, knowledge and ecology synchronously; and also can combine the economic development and ecological protection together to achieve triple effects of economic multiplier, cumulative and radiation.
\end{abstract}

\section{Introduction}

The Communist Party of China pays close attention to agriculture, rural areas and farmers, which is the "Three Agricultural Problems", and especially concerns the livelihood of farmers in poverty-stricken areas. Currently, poverty alleviation and development work is facing a toughest battle than ever before. There exists a high degree of overlap between China's poverty alleviation areas and ecological construction areas; so it needs to take the goals both of reducing poverty and improving the ecological environment into consideration [1]. Meanwhile, it is also the critical period for the coordinated development of economic development and protection of nature environment. The central government combines the reality of poverty-stricken areas together, highlights the concept of green development, and then stresses the issues of ecological and environmental protection in poverty alleviation work. It acclaims that rural poverty alleviation should be guided by the "Two Mountains" thought to achieve sustainable development. Agricultural ecological capital operation operates by treating agricultural ecological resources as a kind of capital. Its aim is protecting ecology in development and developing in protecting ecology. This is a way which can meet the needs of economic development while improving the function of ecological service systems and maintaining the non-reducibility of the stock of ecological capital [2].

General Secretary Xi Jinping has repeatedly stressed: "Resource advantage is invaluable, and the largest resource in underdeveloped areas is ecological resources." Foreign scholars also found that the poor farmers are more dependent on the environment than the relatively wealthy farmers in Zimbabwe [3]. And eco-payment projects that do not aim at "reducing poverty" show good synergy with "poverty reduction" in Latin America [4]. Enshi Prefecture, located in Hubei Province, is a minority autonomous prefecture and also is one of the 14 contiguous destitute areas in the country. As a deep poverty-stricken in whole region, Enshi Prefecture has a difficult poverty alleviation task. Nowadays, poverty alleviation work needs to maximum resource advantages and explores new development methods actively. Enshi Prefecture, where is a good foundation for the coordinated development of ecology and economy, has abundant natural resources and excellent ecological environment. Therefore, studying the function pathways of agricultural ecological capital operation 
in poverty alleviation and exerting the potential productivity of ecological environmental have important practical significance for Enshi Prefecture.

\section{The Effectiveness of Agricultural Ecological Capital Operation in Poverty Alleviation}

Enshi Prefecture has reduced 590,000 impoverished people since the years of 2014. Rural poor population has dropped to 30.08 million. Per capita disposable income of farmers has reached 4,655 yuan. Poverty rate has dropped from $31.3 \%$ to $14.3 \%$. The urban and rural area has undergone significant changes.

\section{Poverty Alleviation Projects Have Been Implemented}

Enshi Prefecture has actively implemented ecological poverty alleviation projects relying on local resource advantages and developed specialties such as oil, vegetables, medicinal herbs and tobacco vigorously. The total output value of agriculture, forestry, animal husbandry and fishery in 2014 amounted to 27.519 billion yuan, which is much higher than in 2013. 4.8 billion yuan. That is owing to the local government promoted ecological projects, which focused on the conversion of farmland to forests, the construction of ecological public welfare forests and afforestation during recent years. Enshi Prefecture completed a total of 1,043,000 acres of forest land and 299,800 acres of forests for returning farmland to forests. The forest cover rate reached $70 \%$, which improves the ecological quality as well as creates 6765 ecological forest ranger jobs for poor people.

\section{Characteristic Industries Have Initially Developed}

The 274 poverty-stricken villages in Enshi Prefecture were lifted out of poverty and the poverty-reducing population was 590,000; and now 534,000 were out of poverty through the industry innovation, which accounting for $90.5 \%$ of it. For instance, since the " $121+\mathrm{X}$ " model (a industrial poverty alleviation way consists with one leading industry, tow industry and finance mutual cooperatives and one leading company) has been implemented, rural characteristic industrial model has been developed to more than 300 million acres. Meanwhile, through creating "Selenium $+\mathrm{X}$ " full industrial chain, the annual output value of selenium-enriched industry grew from 8.3 billion yuan to 38.2 billion yuan.

\section{Poverty Alleviation Funds Have Been Increased}

Through integrating overall arrangements for projects and funds, including poverty alleviation and development, comprehensive agricultural development, ethnic development, accessibility projects, tobacco-based projects and other agricultural resources, a total of 12.11 billion yuan in poverty alleviation funds were consolidated and about 299 million yuan in financial aid loans were instigated in Enshi Prefecture. As the limited resources for poverty alleviation were concentrated on the most urgently needed areas and the most impoverished targets. It can provide more financial protection for the development of the ecological industry and help 100 key poverty-stricken villages and 150,000 farmers out of poverty.

\section{The Function Pathways of Agricultural Ecological Capital Operation in Poverty Alleviation}

The aims of agricultural ecological capital operation in poverty alleviation are solving multiple poverty issues, taking account of agricultural ecological capital accumulation, protecting agricultural ecological environment and achieving multiple effects (figure 1). 


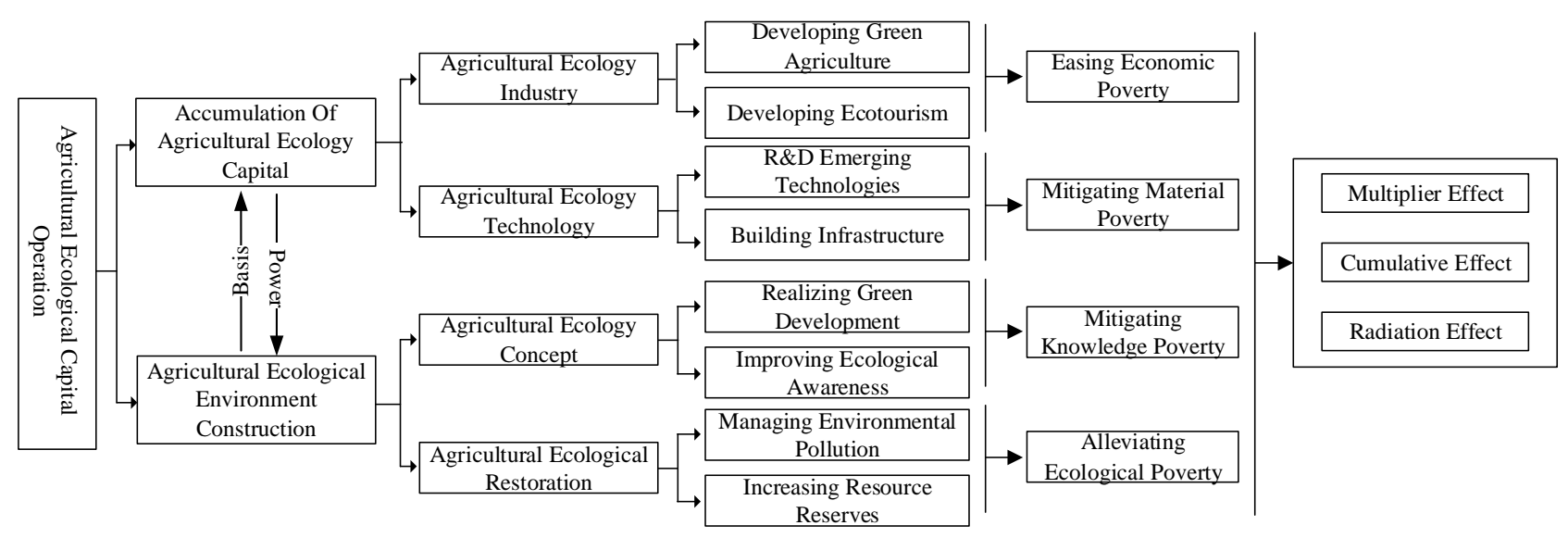

Fig. 1 the function pathways of agricultural ecological capital operation in poverty alleviation

\section{Developing Ecological Industry to Ease Economic Poverty}

Enshi Prefecture promoted the ecological transformation of rural first, second and third industries; and developed the agricultural secondary and tertiary industries through agricultural ecological capital operation. In the prime industry, Enshi developed the courtyard ecological economy and encourages poor households to develop ecological aquaculture species. In the secondary industry, Enshi developed characteristics industries, improved the using efficiency of the infrastructure, reduced the costs of crops, and extended the chain of breeding and product reprocessing. In the tertiary industry, Enshi has vigorously developed ecological tourism and ethnic cultural construction projects and actively explored the development model of "homestay + " in recenty. Through creating kinds of eco-brands and developing ecological industries, the agriculture in Enshi has increased the potential productivity of agro-ecosystems, improved the quality of products and services and enhanced the value of agricultural products. It brings economic benefits to the local area and increases the income of local residents helpfully.

\section{R\&D Eco-Technology to Mitigating Material Poverty}

Ecological technology plays a key role in improving product value through processing and reprocessing ways. The Enshi government paid more attention to cultivate and promote technology. Not only actively carried out research and development of ecological technologies, also increased investment in research and development funds. The advanced eco-technology adds value to resources initial value, transforms product forms and improves the product's attributes. Through processing more varieties of products, farmers can increase the economic value of products and reducing production costs greatly. Eco-technology can increase local productivity and create more economic value.

\section{Delivering Ecological Ideas to Mitigating Knowledge Poverty}

Poverty-stricken areas are rich in resource elements. The deep cause of poverty lies in the lack of awareness and the rational use methods of existing resources. On the one hand, Enshi government combined rural mobility schools with moral lecture halls to introduce relevant agricultural policies and technologies. Which aims to sharing the concept of eco-environment is productivity to farmers, then inspiring their endogenous motives to shake off poverty. On the other hand, Enshi government implemented a strategy called green development strategy. Which helped farmers shared the ecological dividend of green development of agriculture, formed a consensus of ecological protection and increase awareness of environmental protection through the operation of agricultural ecological capital. All of this is knowledge power in poverty alleviation.

\section{Restoring Ecology Alleviated Ecological Poverty}

A good ecological environment is the most popular welfare for the people. Eco-environmental systems have limited carrying capacity. Both the growth rate of ecological resources and the 
purification capacity of ecological environment have a maximum threshold. Therefore, in order to ensure the sustainable development of rural areas, Enshi Prefecture increased the subsidy for ecological protection during the process of agricultural ecological capital operation in poverty alleviation, especially encouraging organic production. For example, farmers who plant organic tea can get $200 \mathrm{~kg}$ per acer of organic fertilizer subsidies and full-process technical guidance; farmers who breed pigs in traditional ways can get 20,000 yuan subsidies and so on. Along with the pollution be treated and ecological environment be restored, the ecosystem can provide more natural resources products and increase the stock of ecological capital.

\section{The Suggestions for Agricultural Ecological Capital Operation to Alleviate Poverty}

\section{Improving Infrastructure Construction}

Infrastructure construction is the basic condition for all poverty alleviation works and development activities in poverty-stricken areas. The government still needs to pay more attention to the construction of infrastructure. For example, the construction of roads should be taken into consideration to build road traffic networks for poor places at first. Which also needs to take the construction of special tourism lines or something else that related to development in to consider when design the road traffic networks. Which means it is not only necessary to solve the problems of broken roads and achieve full coverage of highways in the area; but also take the future economic and industrial development should into plans. Then taking full advantage of the traffic environment after road construction, it should further strengthen the construction of energy and information infrastructure and also needs construct major emission reduction and environmental governance infrastructures. By improving the conditions of infrastructure, Enshi Prefecture can strengthen the internal development and external links, and then provides basic support for the agricultural ecological capital operation in poverty alleviation.

\section{Innovating Industry Development Model}

Industrial ecology and eco-industrialization are specific tasks for integrating ecological civilization requirements into the economic system. Agricultural eco-industrialization and industrial eco-environmental is the only way to poverty alleviation work and also is the inevitable choice of agricultural ecological capital operations. The government can use the power of institutions and organizations such as agricultural enterprises and cooperatives to play their role in processing, helping peasant households, linking markets and resisting risks. In addition, it should strengthen the support for poor villages to develop differentiated village-level features industries and provide direct supports in political, intellectual, material and financial aspects to encourage people develop "hematopoietic" functional projects. Meanwhile, it must emphasize the dominant position of poor households, ensure poor people can get real benefits from it; and then it can stimulate their enthusiasm to participate in agricultural industrialization.

\section{Improving Resource Allocation Efficiency}

Raising the efficiency of resource allocation is an advantage of the market economy and also is a potential goal of economic development. At the initial stage of the agricultural capital operation in poverty alleviation, capital and other resources are limited; and resource allocation is inefficient. As the main resources in agricultural capital operation are natural and ecological resources. It is necessary to use resources, such as soil and water resources, in sustainable ways. On the producing part, people should integrate the concepts of ecological development, improve production technology and change the traditional agricultural production methods. On the marketing part, government should provide rural financial services, improve the market mechanism for property right transactions and create a good property rights transfer platform to make resources flow to more profitable places according to market needs.

\section{Increasing Performance Assessment}

Eco-environmental safety both is an important part of national security as well as an important 
guarantee for economic and social development sustainably and healthily. However, investment in ecological resources is prone to sunk costs. Therefore, it is important to improve the performance of agricultural ecological capital operation in poverty alleviation. To avoid homogenous competition, it needs to develop characteristic industries and increase the diversity of agricultural products. The most important thing is strictly review the construction and acceptance of alleviation projects to make sure it indeed works on poor village's development. At the same time, government should improve the integration and supervision of poverty alleviation funds, strictly review the use of funds at all stages to ensure that improve the overall performance of agricultural ecological capital operation in poverty alleviation.

\section{Conclusions}

A poverty alleviation road, which can reduce poverty reduction costs, optimize resource allocation, take the dual goals of poverty reduction and improvement of the ecological environment into account and stress the sustainability of poverty reduction, would be a very nice way for current situation of China's national conditions [5]. Agricultural ecological capital operation in poverty alleviation, which is promoting the benign interaction between poverty alleviation and ecological construction and realizing the coordinated development of socio-economic development and ecological environment construction, is an effective path to alleviate poverty under the construction of ecological civilization in the new period. With the efforts of the Enshi government, ecological development and economic construction have been combined to carry out various poverty alleviation projects, such as ecological engineering and ecological and characteristic industries. Those efforts have enabled the area to accumulate abundant ecological resources, created favorable conditions for green development and developed multiple agricultural ecological poverty alleviation paths. Agricultural ecological capital operation focuses on agricultural ecological capital accumulation and agricultural ecological environment protection. It works on agricultural ecological industry, technology, and philosophy and restoration mechanism to alleviate the poverties of economy, substance, knowledge and ecology. Then, it can help those areas achieve economic multiplier effect through strengthening the linkage development among agricultural industries, achieve cumulative effect through stacking repeatedly of multiple ecological protection activities at long-term and achieve radiation effect through expanding the scale of regional development. Enshi Prefecture has a good experience in agricultural ecological capital operation to poverty alleviation. It will become much better as it holds a sustainable poverty alleviation way and amend it in the implementation repeatedly.

\section{Acknowledgement}

This research was financially supported by National Natural Science Foundation of China (No. 71673302); National Natural Science Foundation Youth Project (No. 71303261); National Social Science Fund Project (No. 15AZD062).

\section{References}

[1] Liu Hui, Yerkan Uzati, Research on ecological poverty alleviation strategies in western China, China Polity, Resources and Environment, 10(2013):52-58.

[2] Yan Lidong, Chen Guangju, Liu Jialin, et al., Analysis of the elements of ecological capital: a review based on the literature of ecological economics, Journal of Zhongnan University of Economics and Law, 5 (2010):3-9.

[3] Cavendish W, Empirical regularities in the poverty-environment relationship of rural households: evidence from Zimbabwe, Csae Working Paper, 11(1999):1979-2003.

[4] Pagiola S, Arcenas A, Platais G, Can payments for environmental services help reduce poverty? 
An exploration of the issues and the evidence to date from Latin America, World Development, 2(2005):237-253.

[5] Yan Lidong, Chen Sheng, Deng Li, Persistence of green agricultural ecological capital operational revenue: regularity constraints and dynamic control, Journal of China University of Geosciences (Social Sciences), 5(2015):55-61. 